\title{
Poemética: corpo coletivo, narrativas polifônicas
}

\author{
Poemetics: collective body, polyphonic narratives
}

Denise da Silva Mattos; Mônica Rocha

Universidade Federal do Rio de Janeiro

\section{RESUMO:}

Interferência-instalação-poema nômade, criada para ocupar transitoriamente espaços públicos de circulação de pessoas, montada e apresentada pelo coletivo de participantes do Projeto Laboratório de Sensibilidades e Devires - LSD - Extensão da Faculdade de Medicina da UFRJ/Departamentos de Fonoaudiologia e de Medicina em Atenção Primária à Saúde. A Poemética é apropriação livre inspirada nos penetráveis de Helio Oiticica. É ação política que se preocupa em gerar um espaço de libertação usando poesia como dispositivo de escape, falada em voz alta ou gritada dentro de um espaço vermelho protegido. O poema como grito de resistência e de vida diante da opressão que tenta calar. O poema como o "vômito do afogado", como designa Deligny, o sinal que prenuncia seu retorno à vida. Com base nessas ideias, propomos a criação de um espaço que, ao mesmo tempo, acolha o participante e torne sua experiência uma possibilidade de deslocamento.

Palavras-chave: interferência; instalação; sensibilidade; poema

\begin{abstract}
:
Interference-installation-nomadic poem, created to temporarily occupy public spaces for the circulation of people, assembled and presented by the collective of participants in the Laboratory of Sensitivities and Becomes Project - LSD - Extension of the UFRJ Medical School / Departments of Speech Therapy and Medicine in Primary Health Care. Poemetics is a free appropriation inspired by Helio Oiticica's penetrables. It is political action that is concerned with generating a space of liberation using poetry as an escape device, spoken aloud or shouted within a protected red space. The poem as a cry of resistance and life in the face of oppression that tries to silence. The poem as the "vomit of the drowned" as Deligny designates the sign that foreshadows his return to life. Based on these ideas, we propose the creation of a space that at the same time welcomes the participant and makes him / her experience a possibility of displacement.
\end{abstract}

Key-words: interference; installation; sensitivity; poem

DOI: $10.12957 /$ mnemosine.2020.57648 


\section{"Também o coletivo é corpóreo" Walter Benjamin}

Interferência-instalação-poema nômade, criada para ocupar transitoriamente espaços públicos de circulação de pessoas, montada e apresentada pelo coletivo de participantes do Projeto Laboratório de Sensibilidades e Devires - LSD - Extensão da Faculdade de Medicina da UFRJ/Departamentos de Fonoaudiologia e de Medicina em Atenção Primária à Saúde.

A Poemética é apropriação livre inspirada nos penetráveis como objeto onde há interação completa entre o espectador e a estrutura-cor, pois ele se coloca dentro dela (OITICICA, 2011:55). A instalação é uma espécie de cabine, montada com armação de PVC, desmontável, leve, sendo cada face de $0,90 \mathrm{~m}$ de largura por 1,90m de altura, revestida por duas camadas de tecido, tafetá e filó, ambas na cor vermelho sangue, com efeito diáfano. O piso é coberto com uma manta de pelúcia da mesma cor, onde repousa uma caixa grande, também vermelha, preenchida completamente por folhas de papel A4, cada uma com um poema impresso diferente, recolhido aleatoriamente das mais diversas fontes. Completa o conteúdo da instalação um amplificador megafone microfone portátil.

Por ocasião da $10^{\mathrm{a}}$ Semana de integração Acadêmica - SIAC, da UFRJ, realizada em outubro de 2019, inscrevemos a instalação e assim foi apresentada nos anais do evento: “A Poemética surge como uma ação política que se preocupa em gerar um espaço de libertação usando poesia como dispositivo de escape. A partir dela, o leitor pode apreender de diversas maneiras o poema, criando problematizações ou achando nas palavras novo sentido para suas afetações. A poesia tanto permite expressar o nosso mundo existencial quanto nos transporta para outros mundos. A ação proposta atuará como o que Deligny chama de "vômito do afogado" (DELIGNY, 2018), um grito de resistência e de vida ante a opressão que tenta calar a poesia. Daí o nome "Poemética": a poesia como um vômito necessário para a própria existência num momento de afogamento das vozes artístico-políticas. A partir dessas ideias, propomos a criação de um espaço que ao mesmo tempo acolhe o participante e o faz experimentar uma possibilidade de deslocamento. Para isso, será montada uma cabine construída com um pano translúcido de cor vermelha, que atuará como uma cortina de fumaça, dando a sensação de um lugar privado e acolhedor, mas que acessa e é acessível ao exterior. Tomando a ideia de "devoração" das realidades brasileiras, tal como apropriada pelo artista Hélio Oiticica, pretendemos usar a armação de um penetrável - onde o deslocamento do participante altera a 
própria experiência diante das cores da estrutura. Haverá uma caixa no interior da cabine contendo diversos poemas recolhidos pelos extensionistas por toda a Universidade durante os meses que precedem a Semana de Integração Acadêmica da UFRJ. A ação convida o participante a se apossar de um poema aleatoriamente e a lê-lo em alto e bom som. Proporemos movimento, expressão e espaço de desterritorialização e reterritorialização para afetos, possibilitando resultados múltiplos e singulares." (ALOE et alii., 2019)

\section{A montagem do dispositivo.}

A Poemética é a dobra de outra ação do LSD, que a antecedeu e a gerou: a interferência Apirõ, apresentada pela primeira vez no evento "Saberes do Entre: Corpo e Antropofagia", promovido pelo Departamento de Terapia Ocupacional da Faculdade de Medicina da UFRJ, em novembro de 2018. Como a história de uma não existe sem a história de outra, vamos contar as duas de uma vez.

Apirõ é palavra Tupi que significa "acuado". Acuados estávamos naquele triste e inesquecível 18 de outubro de 2018. Acuada estava a universidade no limiar de um tempoespaço que já intuíamos muro, corte, sufocar. Tempo em que palavras que nos acompanharam vidas inteiras como aliadas foram violentadas, despossuídas de seu sentido, hackeadas dos dispositivos humanos em disputa. A palavra como que se esgotou. Sentíamos assim. Vivíamos o limite de seu sentido, o inominável. Nossa roda de conversa do LSD, naquela manhã de segunda-feira, após 18 de outubro, se transformou em comunhão de lágrimas mudas. Mas somos coletivo de criação. E como diz Deleuze, "um criador não é um ser que trabalha pelo prazer. Um criador só faz aquilo de que tem absoluta necessidade.“ (DELEUZE, 1999: 4-5). E o tempo da necessidade produziu em nossos corpos atravessados pelo outubro a criação de uma ação em que a suspensão da palavra colocasse em jogo o estado vibracional destes mesmos corpos. Uma performance dura cujo único som era a batida surda, marcial de um tambor.

Um auditório excêntrico. Corredor muito largo dividindo duas alas de cadeiras, ao fim do qual estava a mesa de apresentação. Na ação, cada um de nós segura, em um vértice de retângulo imaginário, uma fita de isolamento preta e amarela, aquela utilizada para marcar o limite de espaços interditados. Com ela delimitamos território interno no centro do auditório. $\mathrm{E}$ aí, ao som das batidas do tambor, um quinto participante de nosso coletivo deposita, no centro da cena, livros que nos são caros e ratoeiras armadas sobre eles. Ato contínuo. Deslocamos a fita sincronicamente num movimento de expansão do território central dos livros aprisionados. 
Silenciosas e firmes, empurramos com vigor a assistência espantada, fazendo com que se deslocasse para as paredes, limite espacial do auditório, encurralando a todos. Audiência acuada. Acuada. Apirõ. Tupi. Acuados como os povos originários desde a conquista bárbara.

Mergulhamos na experiência dessa corporeidade esgarçada, compartilhada como linha de fuga. Nos estilhaçam a níveis submoleculares? (Re)existimos. Abrimos um novo possível para essa ferida que ainda sangra de forma avassaladora ameaçando nossas existências. Cada participante do coletivo se apropriou do processo de criação do Apirõ e o transformou. Apirõ é performance que propõe uma alegoria paradoxo aprisionante-libertária, na dependência do "se", partícula cinética cujo movimento depende do "quem" que se apossa de um "quando" que invente um "como". Essa performance pode ser pensada como um dispositivo que não dispõe de objetivos, mas que convida à experimentação pelos corpos presentes com possibilidade de criação de sentido. Desse modo, segundo Deleuze (1996), o dispositivo caracteriza-se como máquina de fazer e ver, ou seja, possibilita dar contornos a curvas de visibilidade e de enunciação. O dispositivo promovido pela ação pode gerar inúmeras afetações, com potência de encarnar experiências vividas no cotidiano. Um dispositivo em que a palavra é suspensa, mas faz dizer e ver tantas coisas: o isolamento, a exclusão, o cerceamento, o encurralamento, o esgarçamento da vida, de suas possibilidades, da educação, da saúde, das oportunidades, dos debates, dos sentidos e emoções, do espaço próprio e coletivo. Apirõ foi premiado com Menção Honrosa na 10 ${ }^{\text {a }}$ SIAC da UFRJ, 2019.

Depois de Apirõ, se fez urgente a necessidade ético-estético-política de dar dizibilidade às vozes que o Apirõ fez calar, ou seja, tangenciar o limite do dizível. Muitas conversas no coletivo, extensionistas e docentes propositores do projeto de extensão, sobre como nos apropriarmos da palavra esgarçando-a para extrair dela novo sentido. Nessa esteira, o LSD propõe abrir um campo de possibilidades de alargamento do sensível por meio do encontro, entendendo este como uma operação de reciprocidade em um tempo intensivo, uma ferida recíproca com potência despertadora de afetos inesperados. Nesse sentido, os encontros são disparados por cada uma das ações do LSD e percebidos como tempo-espaço-interferência. O encontro como ferida tão delicada quanto brutal, alargando o possível e o pensável, sinalizando outros mundos e outros modos para se viver juntos, subtraindo passado e futuro com a sua emergência disruptiva. (EUGENIO et allii., 2012). Que interferência-palavra poderia nos lançar nesta experiência de encontro? O poema?! 
A dobra de Apirõ seria o poema, o estatuto da palavra capaz de enfrentar seus violadores embrutecidos. Intuímos que o poema teria potência para tal. E mais: o poema lido em voz alta! O poema lançado a plenos pulmões! O poema como grito de resistência e de vida ante a opressão que tenta calar. O poema como o "vômito do afogado", como designa Deligny o sinal que prenuncia seu retorno à vida. O Poema, o vômito, emético... Assim nasceu o nome: Poemética. O vômito redentor dos afogados de outubro. Arte como ato de resistência, como o que resiste à morte (DELIGNY, 2018).

Poemética. A energia potencializadora de uma nova ação voltava a circular no coletivo. Todos queriam coletar poemas no campus. Ler poemas em voz alta. Pronto! Pronto? Não! Porque eis que uma nova extensionista lança o desafio, que é para muitos: "Eu não sei se conseguiria sair lendo em público, em voz alta". A solução proposta: dizer sem ser vista. Mas como ocultar o leitor e soltar a voz? Coletivos de trabalho têm esse caráter singular do circular. A medida do desafio é o crescendo de novas perguntas. $\mathrm{O}$ nosso agora era como operar a disjunção entre o visual e o sonoro, ou ainda, entre "quem" o enuncia e seu receptor. Um véu, uma cortina... Alguém propõe uma cabine. Ao que outra emenda: um penetrável. E vamos revisitar Hélio Oiticica. Apropriação livre do penetrável. Agora é só fazer! Só fazer... Como se fosse possível uma separabilidade de pensar/idealizar e fazer/ação. Aí se localiza uma das apostas do LSD: as experimentações de suas ações, a abertura ao processo criativo e em acontecimento.

Se a criação é necessidade nossa, também é dos materiais. E criar a partir deles é perceber as exigências de suas texturas e possibilidades como se eles, independentemente de nossas intenções de modelagem, nos dissessem: “Assim não será possível”. E daí são eles, os materiais, que vão nos dando pistas, acesso a suas vidas próprias ao cederem ao nosso manuseio para sua utilização ou nos interditando. Essa foi uma experiência formidável. Compartilhar a vida dos objetos que nos dizem coisas! Trabalhar o encontro em que ambos nos tensionamos, nos alegramos, sofremos, negociamos um caminho possível compartilhado.

Decidimos produzir a estrutura da cabine parte transformando o que já tínhamos no acervo e parte adquirindo o necessário, ao menor custo. Foram dias e dias de aprender fazendo. Cálculos de medidas precisas para encaixes de um quebra cabeça. Panos e seu ajuste ao suporte. Quem sabia costurar, costurou, quem sabia articular, articulou. Quem não sabia também. Todos tivemos que aprender. Vermelha. Uma instalação toda vermelha, encharcada na ideia de Oiticica que se invadia de cor, tocava, pisava, respirava cor. (PEDROSA, 2004) 
A pintura da armação vermelha seria como? Uma das estudantes propôs usarmos spray. Mesmo usando máscaras não poderíamos fazê-lo em nossa pequena sala de trabalho. Descobrimos no campus da Praia Vermelha - UFRJ um espaço baldio, chão de terra batida no entre árvores, junto a poucos operários que trabalhavam. O (des)lugar deu lugar. Exceto pelo vento que rodopiava e fazia cada jorrar de tinta spray uma espécie de dança-fuga improvisada para que não nos pitássemos junto com as peças da armação. Nitidamente aprendizes. Éramos quatro na aventura em curso. Um dos operários se aproximou. Ele observava a tudo curioso pelo inusitado da situação naquele espaço sempre vazio, extensão do barracão de obra. Em silêncio começou a improvisar conosco na busca de um ângulo com apoio favorável ao trabalho, na tentativa de burlar o vento no espaço aberto. Agora éramos cinco no arranjo tácito que o acontecimento agenciou. De repente ele soltou: “O que é que vocês estão fazendo?” Ao que respondemos que uma espécie de caixa para dizer poemas dentro dela. Ele emendou de batepronto: "Eu não sei o que é poema".

"Eu não sei o que é poema" foi o enunciado inesperado que nos acionou. Nós nos entreolharmos com a surpresa da descoberta do desafio posto: ao fazer falar, como responder produzindo língua que estabeleça conexões? O curso quase hiperbólico do pensamento fez conversa:

- Sabe o que é verso? Como fazem os repentistas que vão rimando enquanto cantam? Ele sorriu satisfeito ao se perceber agora dentro do grupo.

- Isso eu sei!

- Então, poema é um tipo de verso. A gente quer convidar pessoas para falarem versos, poemas bem alto, em público. Você falaria?

- Não.

- Por quê?

- Ia ter vergonha

- Mas e se você pudesse gritar escondido, dentro de uma espécie de caixa grande, você toparia?

- Ah, aí eu falava!

- Então, ... é isso que a gente está fazendo aqui. Uma caixa vermelha onde as pessoas que têm vergonha vão poder falar bem alto os poemas que quiserem.

Retomamos o trabalho. Nosso interlocutor, visivelmente satisfeito, nos deu dicas de como fazer. Ao fim da tarefa da manhã nos despedimos. Transformados pela pequena descoberta no encontro. 
A Poemética foi encarnando em cada corpo do LSD. E emergiu com uma potência que transbordou dos diários cartográficos dos estudantes. E só lendo para sentir:

"Retomando as atividades no projeto neste segundo semestre do ano, voltei com uma expectativa a qual sofreu uma torção ao longo dos nossos encontros nestes meses. Achava e esperava que íamos realizar atividades semelhantes às que experienciamos no último semestre, com leitura de textos, confecção de mapas, realização de atividades/performances/interferências na rua, trocas e discussões sobre textos, sobre buscas ativas, sobre experiências em geral, sobre o contexto em que vivíamos, e por aí vai... Mas, com a SIAC se aproximando, nos ocupamos principalmente em dar, fazer, tomar corpo nossas construções artísticas. Assim, nos dedicamos manualmente para esta materialização, deslocando totalmente o que eu esperava, de modo que minhas expectativas foram se transformando e fluindo para outro caminho, interagindo e se integrando a esse outro convite, um convite-processo, que foi se construindo/sendo construído em movimento, não estando pré-estabelecido e duro. Um convite de colocar a mão na massa, de manufatura afetiva.

$\mathrm{Eu}$, que nunca tive muitas habilidades e coordenações manuais, hesitei um pouco e me frustrei diante desse convite, me colocando numa posição meio defensiva e sem me jogar de cara nessa nova conformação que estava se dando no projeto. Fui tomada por pensamentos como "será que é só isso que a gente vai ficar fazendo ao longo do semestre todo?", sem imaginar o tanto que veio com esse "só", o tanto de sentimentos, o tanto de sutilezas transformadoras e que me marcaram, o tanto de encontros e trocas possíveis... Aos poucos fui me abrindo a esse convite em constante processo de construção e fui surfando em novas ondas, abrindo novos caminhos, fazendo e aprendendo na prática com M., B., D., A. Habilidades de costura, de corte, de medição, de pintura, delicadezas manuais. Fomos ao Centro escolher os tecidos e depois de algum tempo andando por aí, pesquisando, vendo e combinando muitos deles para dar aquela sensação de proteção e anonimato, mas ao mesmo tempo sem invizibilizar quem fosse estar por dentro da estrutura da Poemética, como também o mundo afora, e uma sensação LSD, com um certo efeito de alteração dos sentidos ou ilusão, por exemplo, conseguimos encontrar uma combinação perfeita de tecidos vermelhos... Fui acompanhando todo o processo de confecção dessas nossas ideias que tomaram corpo e tomaram vida própria, desde suas idealizações, a confecção de seus esqueletos, órgãos, a impressão de nossos afetos, mãos, marcas, histórias. E todo este processo foi tão leve e intenso ao mesmo tempo, permeado por tranquilidades e ansiedades, foi tão aconchegante, foi um espaço de respiros e trocas, um espaço acolhedor em meio a essa vida turbulenta, corrida, acelerada. Parece que se estabelece uma outra temporalidade quando estamos coletivamente no LSD, temporalidade outra que abre espaço para um estar e viver leve.

Cada dia mais próximo desse grande evento para o qual nos preparamos inteiramente neste semestre. (...) Ainda tínhamos que finalizar várias coisas para o dia seguinte, costura da Poemética, tecido vermelho para lá para cá, corte de moldes, poucas tesouras, muitas pessoas, muitos estímulos, muitas conversas, muita saudade, muitos encontros, rapidez, vontade de estar com todas mas ao mesmo tempo de me retrair, de respirar, de ser acolhida....

Fui seguindo o fluxo do meu jeito..."

Assim a Poemética foi ganhando sua (i)materialidade na medida dos atravessamentos.

O objeto-dispositivo como obra-potência prestes a estar no mundo, ao sabor do que cada um dela fizesse, como uma espécie de engendramento autopoiético. Interferência-instalaçãopoema nômade criada como lugar quase em hipérbole para agenciar outras criações em devir. O convite à experiência está inscrito em seu próprio corpo vermelho provocante, oferecido em espaço aberto. Aqui seria colocada uma figura, mas pensando bem, nenhuma imagem 
bidimensional "muda" traria a potência da afecção. Então, a imagem será a construção interior de cada leitor a partir da descrição aliada a sua própria imaginação. E ao convite...

Olá! Poemética é um convite!

Tire seus sapatos Entre

Sinta-se a vontade Pegue um poema RECITE! GRITE!

Se desejar, use o alto falante

Vomite seus afetos com poemas 


\section{O corpo coletivo: Poemética no mundo}

A Poemética então começou seu caminhar como corpo ativo, acontecimento entre pessoas, na Semana de Integração Acadêmica da UFRJ. Dividindo um amplo espaço com outros trabalhos de diferentes escolas em frente à biblioteca do Centro de Ciências da Saúde. Professoras e estudantes transportamos e montamos juntas a instalação. A ansiedade nos tomou. Como funcionaria nosso dispositivo de polifonias poéticas?

E a Poemética aconteceu. Vieram tímidos e ousados, tranquilos e agitados, ocupados e apressados, todo tipo de gente curiosa. E cada um se entregou à proposta sensível de modo singular. Retiravam os sapatos, entravam na instalação e se seguia o silêncio. Se houvesse menos ruído do ambiente, talvez pudéssemos ouvir o murmurar de cada folha de papel deslizando sobre a outra. Até que, por fim, o poema era escolhido no maravilhamento do encontro. Drummond, Clarice, Barros, Hilda, Bandeira, Cacaso, Waly, Leminski, Augusto, Décio, Arnaldo e tantos outros como a pulsar. Então, a voz amplificada explodia num jorro, retomando para as palavras seu lugar de múltiplos sentidos que foram transmutados da interferência do Apirõ. Cada passante se voltava tentando definir quem falava, mas a Poemética só deixava ver uma silhueta vermelha...

A estudante narra:

"Chega o dia. Uma mistura de afetos sentia. Um misto de ansiedade, receio da avaliação, alívio pois tinha chegado o dia e tínhamos conseguido gestar nosso bebê, tristeza porque M., que foi fundamental na construção da Poemética e acho que sem ela não seria possível, não conseguiu estar presente, admiração, vontade e animação para que as pessoas aceitassem o convite da Poemética, experimentassem e deixassem ser levadas por aquela vivência vermelha, fortes expectativas....

O momento de carregar a estrutura da Poemética pelo CCS e ao mesmo tempo tentar encontrar o lugar que íamos ficar, para mim foi parte do processo de parto, porque realmente foi um parto essa etapa final. Mas um parto nada dolorido e muito divertido, que contou com muitas mãos e muito desejo.

Junto com maravilhosas exposições, projetos, apresentações, outras obras de arte, a Poemética ficou.

As vozes gritantes que soavam e ecoavam de lá iam compondo a totalidade indevir, inacabada, interminável movimento de construção composição costuração.

Poemas vivos

Vivas vozes

Ruídos potentes no espaço

De um espaço duro, rígido, apagado, cinza

Se fez um espaço vivo, sensível, afetado

Dentro e fora

Fora e dentro

Ali por aí por aqui". 
No LSD os encontros são disparados por ações que se dão na forma de interferências. Entende-se interferência, a partir do latim, como processo de produção de feridas e escoriações mútuas, necessárias entre corpos que se dispõem à experiência do encontro. Interferência é ação, a modo das ondas de rádio, ondas curtas, no sentido de uma intromissão (HENZ et alii., 2017). Sem expectativa de qualquer reação ou desdobramento pré-definido. É abertura ao devir. Diferentemente às intervenções que, em geral, implicam numa relação de causa e efeito. Nossa oferta é reunir experiências de alargamento do sensível no encontro, principalmente aquelas pautadas em conhecimentos e práticas classicamente definidas como marginais na academia, articulando a miríade de possibilidades da arte. É espaço-tempo de experimentação artística coletiva e reflexão sobre suas possibilidades de operar no afrouxamento das bordas do sensível, envolvendo todo o quadro social da universidade, entre técnicos, docentes, estudantes e quem mais quiser participar e produzir interferências que se propaguem para fora do laboratório. Propõe a realização de atividades de experimentação artística e reflexão sobre suas possibilidades de operar no afrouxamento das bordas do sensível. Operando zonas de vizinhança entre o corpo, a arte, a filosofia, a política e a ciência.

O esforço desse projeto é vazar e fazer linha de fuga no automatismo do pensamento. Vazar da sua forma organizada e sistematizada em universais, enfrentar e não inibir a experiência do caos, do imprevisível, do não saber dizer. Produzir intercessores a partir da experimentação do sensível e produzir alteridades capazes de nos colocar frente a problemas ainda não formulados. Abrindo fendas, rachaduras para processos de desterritorialização, reterritorialização. Tentando criar um campo de reviragem da sensibilidade.

A Poemética ganha vida própria e se lança em novas oportunidades de experimentação, em diversos coletivos.

\section{Chegamos, UERJ!}

O convite à participação no evento "Políticas e poéticas do contágio: ensaios de viver entre muitxs", promovido pelo Instituto de Psicologia da UERJ, nos chegou como convocação. Pirar junto como produção militante de sociabilidade criadora que nos faça escapar do nevoeiro denso da distopia que nos envolve desde aquele outubro. Não por coincidência, um certo exercício de imaginação social semelhante ao que nos fez necessitar da Poemética. E criá-la. E desejar fazê-la circular em fluxo. 
Res-pirar, trans-pirar, cons-pirar. Costurar outras tessituras vitais. Outros arranjos, encontros na encruzilhada entre arte, política e subjetividade, para reaprendermos juntxs a viver juntxs. Em disputa. De dentro do nevoeiro que não cede à tentativa de resgate de algum elemento empático com a vida. O convite finalizado com a pergunta: Vamos?

"Vamos, claro que sim!" E de pés juntos caímos para dentro dessa aposta. Respondemos com o estado vibracional de nossos corpos ainda impregnados com o que fora experenciado no evento da SIAC duas semanas antes desse encontro na UERJ. Transporta, monta, encaixa, veste, preenche, deposita, convida, poema, Ana Cristina, Torquato, Capinam, Caetano, voz, palavra, agenciamento, vida, vermelha.

Por fim, lá estava ela, como paisagem de resistência, instalada no hall do $10^{\circ}$ andar onde acontecia o evento. Na saída da rampa, que faz a ligação entre os prédios da UERJ, logo se podia avistá-la. O contraste do vermelho sangue com o cinza/concreto do espaço e da arquitetura fria daquele prédio convidava a aproximação dos passantes para ver e experimentar. Ela fez liga. Ela fez rede naquele espaço porque se abriu uma brecha desejante. O único suporte que possibilita a rede é a brecha... (DELIGNY, 2015)

Não temos ideia de quantos lá pararam e se experenciaram com a poesia e o mergulho na vermelhidão uterina da cabine. Quantas vozes ecoaram cortando a névoa densa. Lorca, Brecht, Baudelaire, Akhmátova, ... Cada participador se integrou ao objeto e o transformou para si. Para nossa surpresa, alguns produziram outra operação, deixando bilhetes e suas próprias poesias na caixa vermelha. Silva, Souza, Santos, Rocha... O contágio operou! E a Poemética fez nova dobra.

$\mathrm{Na}$ tarde do último dia do evento participamos com representantes de outros coletivos da roda de conversa "Cons-pirações-ensaios de viver entre muitxs", cuja proposta era a circulação das apostas dos diversos grupos, seus modos de operação e produção e suas respectivas pirações-ensaios. A boa conversa é aquela que sempre deixa algo a ser dito, que escapa ao momento, mas que pela dimensão polifônica da circulação da palavra em roda e em reverberação dos corpos, numa política de contágio, não cessa em fazer dizer mais alguma coisa...

Deste modo, procuramos dividir com você, leitor deste texto, o relato da experiência. $\mathrm{O}$ que foi dito... e o que restou a falar de nossa aposta do LSD fazer rede em cons-pirações-ensaios coletivos. Numa relação de co-existência. 
Como retribuição a você que chegou até aqui contando apenas com a imaginação para visualizar a Poemética narrada ... tire seus sapatos, entre, sinta-se à vontade, pegue um poema, https://www.facebook.com/laboratoriodesensibilidadesedevires/videos/474730733129207/

"Nós somos os propositores: nós somos o molde, cabe a você soprar dentro dele o sentido da nossa existência.

Nós somos os propositores: nossa proposição é o diálogo. Sós, não existimos. Estamos à sua mercê.

Nós somos os propositores: enterramos a obra de arte como tal e chamamos você para que o pensamento viva através de sua ação.

Nós somos os propositores: não lhe propomos nem o passado nem o futuro, mas o agora."

Lygia Clark

\section{Referências}

ALOE, Gabriella; FRÓES, Lorena Zikan; PASQUAL, Victória Benfica Marra; GARCIA, Juliana Bueno; DIAS, Isabela Fernandes Prado; TELDESCHI, Maria Clara Conforto; OLIVEIRA, Rafael Grillo Fernandes; MACEDO, Ana Paula Aguiar; MADY, Beatris Maria Carvalho; PIRES, Nathalia Massi; ROCHA, Monica Moreira; MATTOS, Denise da Silva.

Poemética, https://sistemasiac.ufrj.br/cadernoController/gerarCadernoResumo/35000000, acessado em 27 de maio de 2019.

DELEUZE, Gilles. O ato de criação. Folha de São Paulo, São Paulo, 27 jun. 1999. Caderno Mais!

DELEUZE, Gilles. O mistério de Ariana. Lisboa: Ed. Vega - Passagens, 1996.

DELIGNY, Fernand. Os vagabundos eficazes. São Paulo: Edições n-1, 2018.

DELIGNY, Fernand. O aracniano e outros textos. São Paulo: Edições n-1, 2015.

FIADEIRO, João; EUGENIA, Fernanda. Secalharidade como ética e como modo de vida: o projeto AND_Lab e a investigação das práticas de encontro e de manuseamento coletivo do viver juntos. Urdimento, no 19, p. 61-69, nov. 2012.

HENZ, Alexandre Oliveira; RODRIGUES, Andre; CAPOZZOLO, Angela Aparecida SANTOS, Carlos Eduardo Alves; LIMA, Eliana Rocha; Gustavo Lucas Bardelli de CORDEIRO, Gustavo Lucas Bardelli; MORENO, Harete Vianna; ALMEIDA, Lara Aparecida Machado; SILVA, Maria José; Rafaela Camargo BALDO, Rafaela Camargo; CASETTO, Sidnei José; PEREIRA, Tahamy Louise Duarte; LIMA, Thayara Paule Herrera. Cabeça dizpensa, corpo desvago: experimentações de um Laboratório de Sensibilidades. Fractal: revista de psicologia , vol. 29, p. 96-102, 2017.

LABORATÓRIO DE SENSIBILIDADES E DEVIRES/LSD. Poemética SIAC UFRJ. 22 de outubro 2019. Disponível em: <https://www.facebook.com/laboratoriodesensibilidadesedevires/?ref=bookmarks $>$. Acesso em 27 de maio de 2020. 
OITICICA, Helio. Museu é o mundo. In: OITICICA FILHO, César (org.). Helio Oiticica. Rio de Janeiro: Beco do Azougue, 2011.

PEDROSA, Mario. Acadêmicos e modernos. ARANTES, Otília (Org.). Mario Pedrosa. São Paulo: EDUSP, 1998

ROCHA, Monica.; SANTOS, Adriana. Rosa C.; RESENDE, Catarina. Polissemias do sensível: resistência e ethos na formação em saúde. Interritório, v. 5, p. 124-139, 2019.

Denise da Silva Mattos

Faculdade de Medicina. UFRJ. Rio de Janeiro

E-mails: denimattos@gmail.com

lsdufrj@gmail.com

Mônica Rocha

Faculdade de Medicina. UFRJ. Rio de Janeiro

E-mails:monicarochaufrj@gmail.com

lsdufrj@gmail.com 